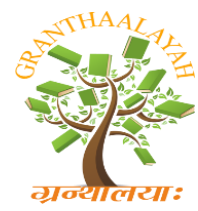

Arts

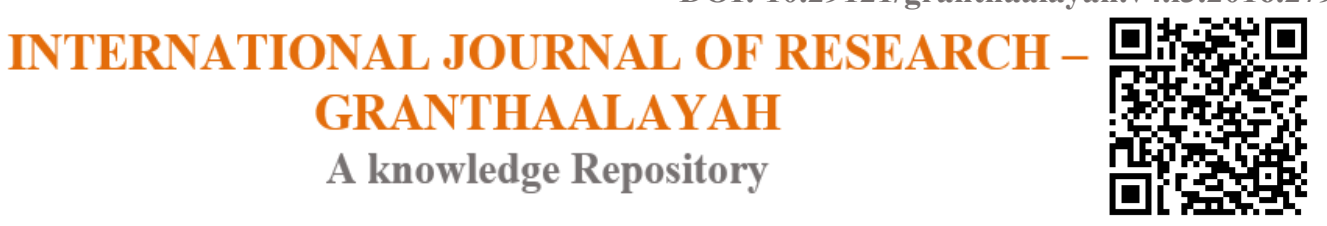

\title{
BIDRI WARE: A UNIQUE METAL CRAFT OF INDIA
}

\author{
Dr. Anjali Pandey ${ }^{* 1}$ \\ ${ }^{* 1}$ Assistant Professor \& HOD, Department of Drawing \& Painting, Govt. M.L.B. Girls P. G. \\ Autonomous College Bhopal, INDIA
}

\begin{abstract}
Handicrafts are valuable; they make our life enriched by their grace. Many times the question rises in our mind, about the origin and concept of the art and craftsmanship, its method and technique, material and attribute of the craftsmanship. The master craftsmanship of Bidri ware has all requisite qualities of excellence. Bidri is a type of encrusted metal ware. It is an intricate process involving several steps. Its preparation process and manufacturing is unique. The decorative designs describe the influences of Mughal impact. Often Bidri ware had inscription Arabic calligraphy of high quality. The metal commonly used is an alloy of copper and zinc. The zinc content gives the alloy deepan black colour. Bidri artist used simple and handmade tools for working. The textural ornamentation by hammering, engraving, inlaying creates the unique decorative effect Mainly six techniques -Aftabi, Koftgiri, Tehnishan, Zarbuland, Munabatkari and Tarkashi are used for ornamentation. Huqqa, Pandan, Surahi, Lota, Thali, Katora, Battle shield, sword etc are the main articles of Bidri ware. Today the Bidri artisans made some changes for new up comings.
\end{abstract}

Keywords:

Engraving, ornamenting, Bidar, calligraphy, metal alloy, Inlay, silver wire, polishing, skillful designs.

Cite This Article: Dr. Anjali Pandey, "BIDRI WARE: A UNIQUE METAL CRAFT OF INDIA" International Journal of Research - Granthaalayah, Vol. 4, No. 3 (2016): 170-175.

\section{INTRODUCTION}

"The craftsmen of India have always shown an exceptional skill of engraving, chasing and ornamenting of gold and silver articles in everyday and decorative use."1

Metal wares are mainly used for necessity, religious and ritualistic purpose. Bidri ware is unique metal ware with sparkle of silver designs on black background; originates from the township of Bidar which was the part of Hyderabad and now in Karnataka State. ${ }^{2}$ The fine specimen of ancient Indian metal craft was found to be filled with coral beads, sapphire, rubies, crystal and pearls. It is a casket of 1 st Century B.C. found from excavation of Buddhist site of Jalalabad. ${ }^{3}$ 

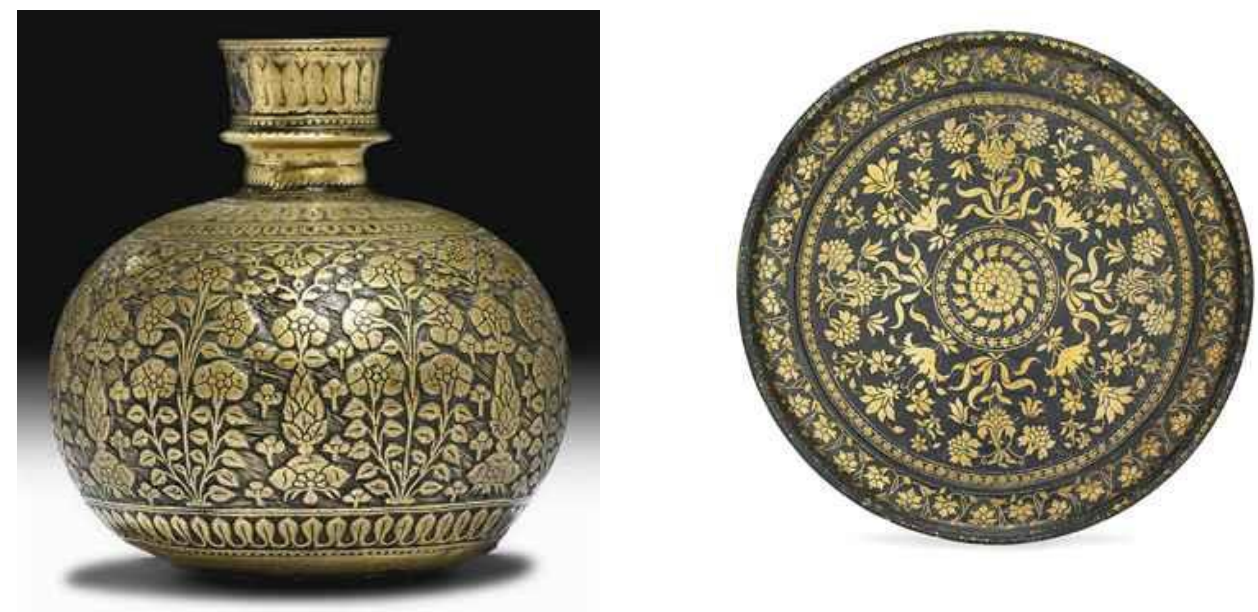

"The Hindoos have since time immemorial not only excelled their neighbors in the management of metals for useful and curious purposes but are even familiarly acquainted with alloys unknown to our practical chemist"4
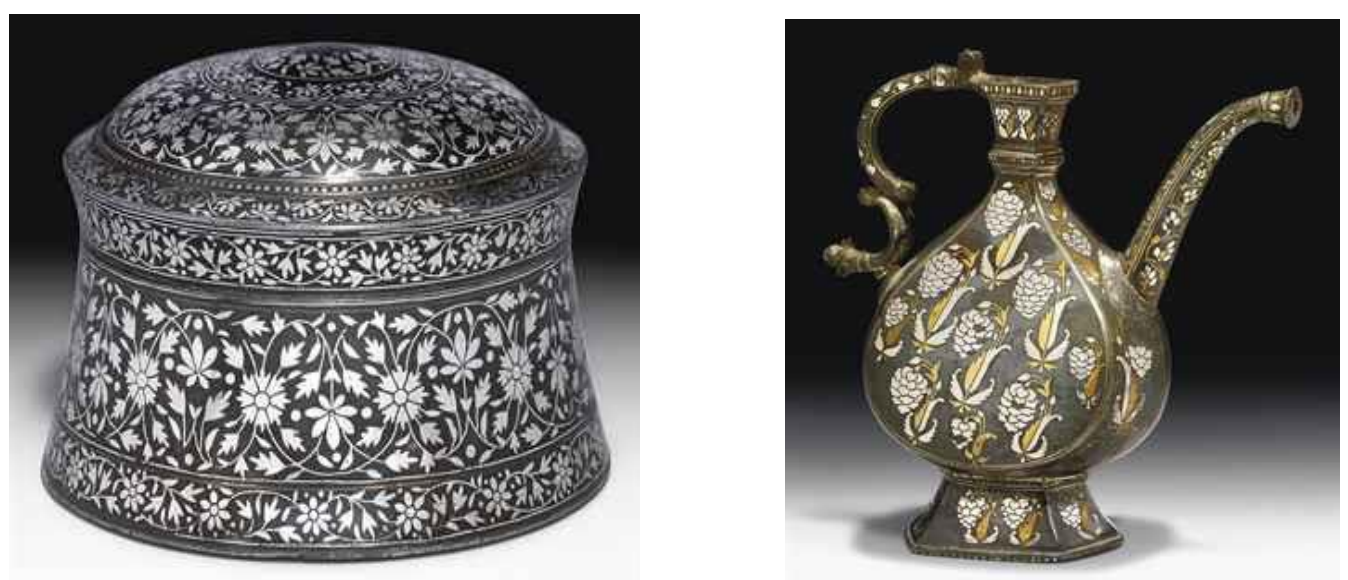

\section{ORIGIN}

The origin of Bidri art is obscure. It is commonly believed that it was originated in Iran or Iraq from where it migrated to Ajmer with the Sufi Saint Khwaja Moinuddin Chisti, thereafter it transferred to Bijapur. During the rule of Bahmani Sultans in the $14^{\text {th }}$ century it flourished and Bidar became the reputed city for artisans. The important centers of Bidri ware are Lucknow in U.P., Murshidabad in West Bengal, Purnia in Bihar ${ }^{5}$ and Maharashtra. ${ }^{6}$

\section{RAW MATERIAL AND TOOLS}

Zinc, copper are the prime raw material of bidri ware, copper sulphate is used. Silver, copper wires are used for inlaying.

Bidri artist used simple and handmade tools for working. Chisel is used to engrave the design. For smoothing the surface file, sand paper and buffing blades are generally used. Scraper, scissor, saw, tong, peeler, hammer, filers, rasps are also used while cutting, engraving and 
inlaying process. Brushes are used for polishing and to applying the solution. Groundnut oil and charcoal is applied to deepen the black matt coating. Bidri fort mitti-clay Sangzeera is applied on products to give permanent black colour. ${ }^{7}$
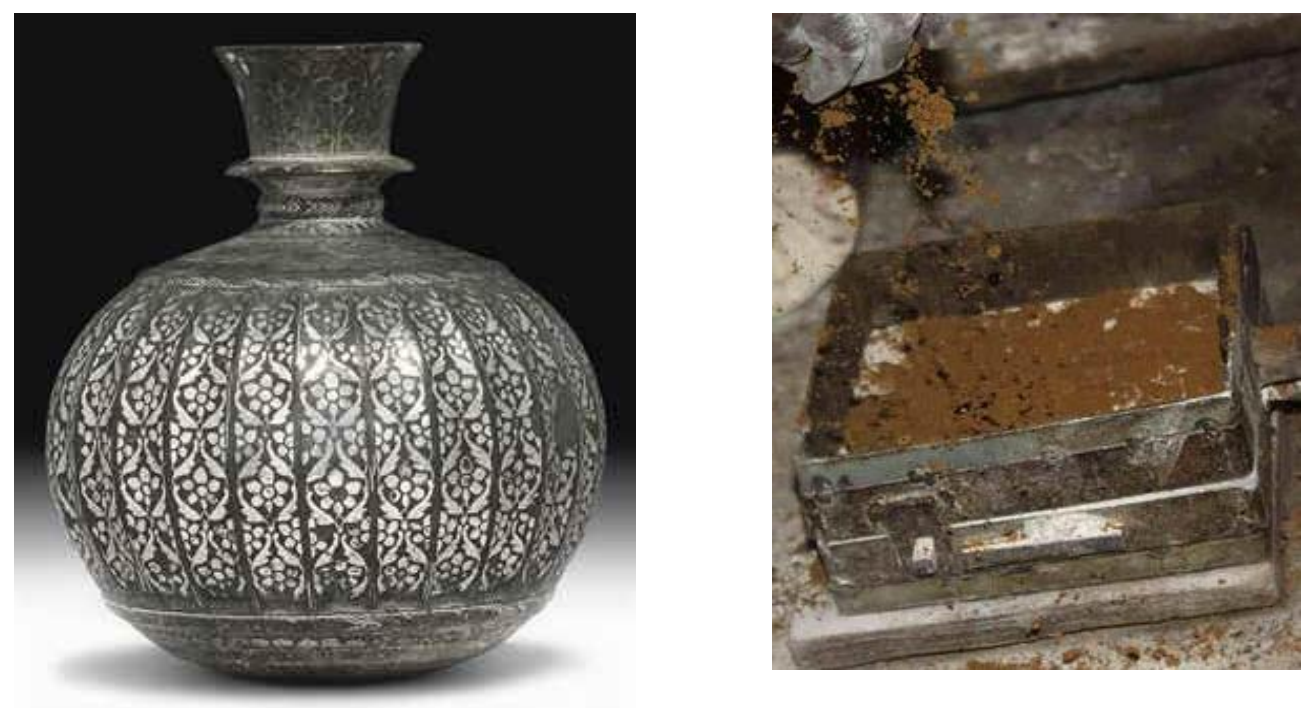

\section{PROCESS}

"Bidri ware is metallurgical compound and the articles made for it are always greatly admired for the elegance of their form and gracefulness of the patterns with which their surface is covered. Although the ground work of the composition appears to be black, its natural color is that of pewter or Zinc."

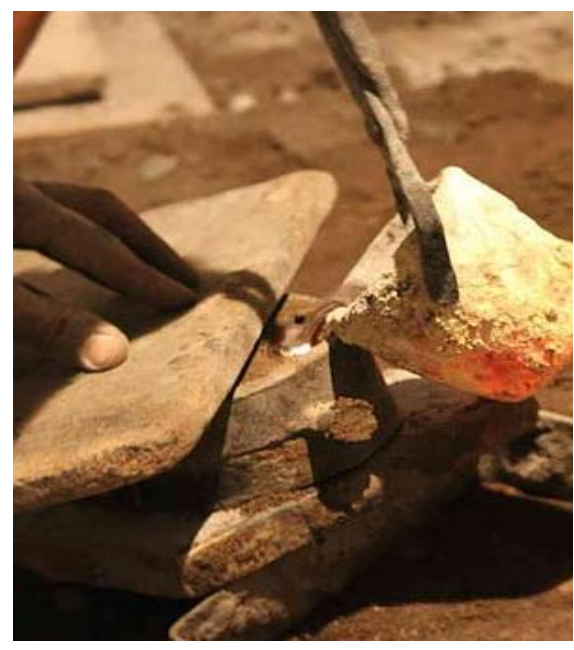

The process of Bidri ware is in the form of encrusted metal ware in which one metal is inlayed on to another metal. His process is performed in four steps- molding, carving, inlaying and oxidizing. ${ }^{9}$

Firstly craftsman cast the item by molding. He used the mixture of red and fine clay and cow dung for making the mould. Zinc and copper in the proportion of 16:1 with other non-ferrous metals is used to prepare the solution. This molten alloy solution is poured into the vacant space of mould. ${ }^{10}$

In second stage, they dipped the vessel into the copper sulphate solution for blacking the metallic surface. This procedure helps the designer to draw the design on dark surface. The kalam (engraving tool) or metal chisel is used to draw and engraving of the design. The delicate tapestry of design reflects the refinement of the design. The designs are drawn free hand. ${ }^{11}$ After designing; the item is handed over to inlayer. Brass, silver or gold is used for inlaying. ${ }^{12}$ Accordingly artisans prefer silver for inlaying. A thin plate of silver inserted in cavity by hammering, with the help of steel point chisel. Scrapper (randa) is used for smoothing the surface. 

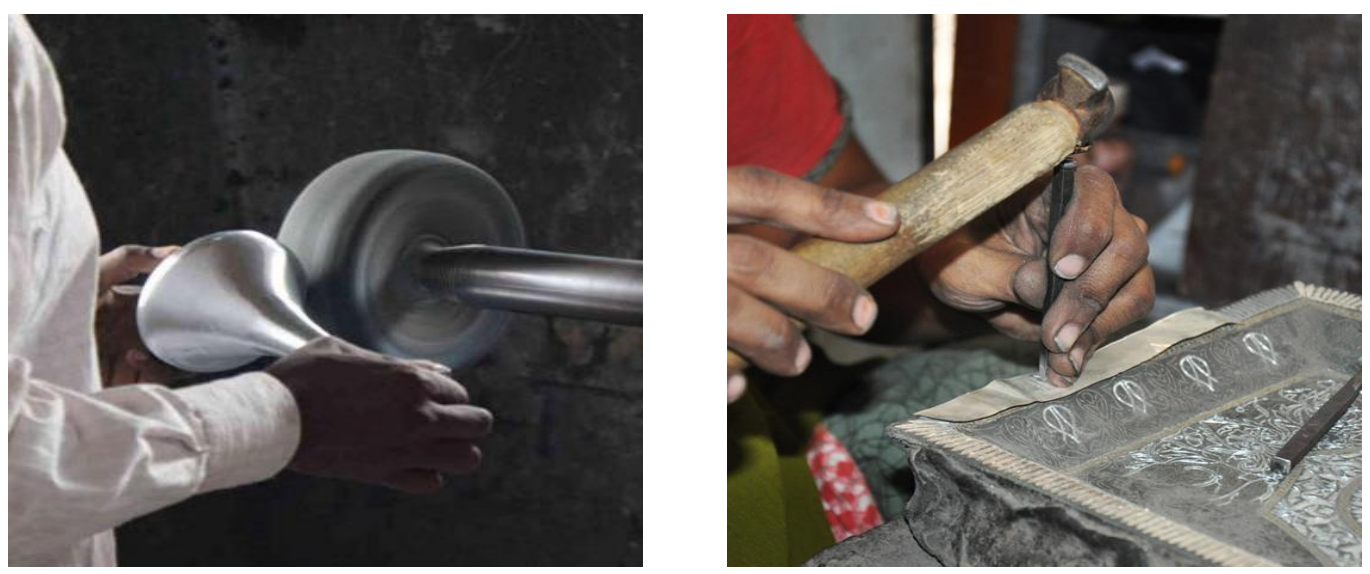

Blackening is the fourth stage which marks the process of imparting a permanent black colour on the surface without damaging the inlay. ${ }^{13}$

"For blackening the base material sulphate containing salt ammoniac are mixed in sufficient water in the ratio of 30;5 and the solution is boiled in an open iron vessel on a charcoal hearth. The finished article is then given a dip in this hot solution. The effect is magical. The zinc alloy turns permanently jet black while the silver retains its brilliance." 14 Lastly they polished the article by the paste of charcoal powder mixed with groundnut oil. A small quantity of paste is sufficient for the polish. They rub it several times on the surface from the thumb or muslin cloth for the good shine. After that the item is heated little and allowed to dry then they cleaned it properly with water or oil. ${ }^{15}$

\section{DESIGNS}

"Man had discovered geometry and the sacred nature of the abstract and had evolved simple tools for the measurement of angles: this enabled him to build with precision and accuracy." ${ }^{16}$ The major motifs are influenced by Mughal motifs; Geometrical and floral patterns also included in the motifs. The artisan inlays new design, but the traditional designs are more in demand. The designs influenced with Persian pattern are circular flower with five petals, angles, lines, dots, spirals, creepers, chequer, fish scales etc. In Hindu pattern Swastic, lotus, human figures can be seen. Birds, animals, fishes are also depicted. Some vessels have illustrative scenes or inscription. As the designs are freehand so it requires much more perfection and skill. ${ }^{17}$

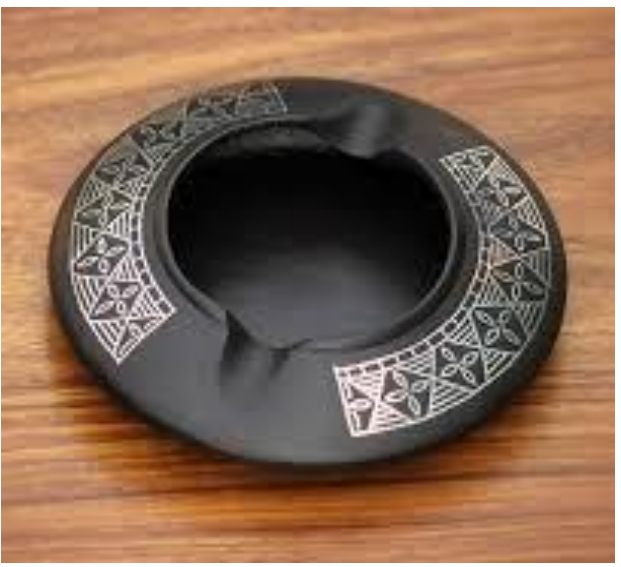

Mainly six techniques are used for ornamentation they are: Aftabi(cut out design in metal overlay), Koftgiri, Tehnishan(inlay of sheet metal), Zarbuland(pattern in high relief), Munabatkari and Tarkashi (inlay of wire). Aftabi and Munnabatkari have slightly raised levels patterns of designs from the level. Tarkashi is metal wire inley work. Zarbuland and Tehnishan have deep grooves. $^{18}$ 
Utility is the necessity part of completeness of life. The articles with Bidri designs are Huqqa, Pandan, Surahi, Lota, Thali, Katora, Small box, Spittoo, Battle shield, sword etc. ${ }^{19}$

\section{CONCLUSION}

India is old in experience but young in modernity. Since centuries the craftsman are continuing his vocation as a part of his service to the community. Today the Bidri articles have some changes. The new up comings are Cigar boxes, ash-tray, cigarette case, match box, cuff links, fruit boxes, flower vases jewelry etc. ${ }^{20}$

According to Jadish Mittal "The Bidri craftsmen did not belong to a hereditary artisan caste, like the goldsmith, coppersmith, ironsmith,

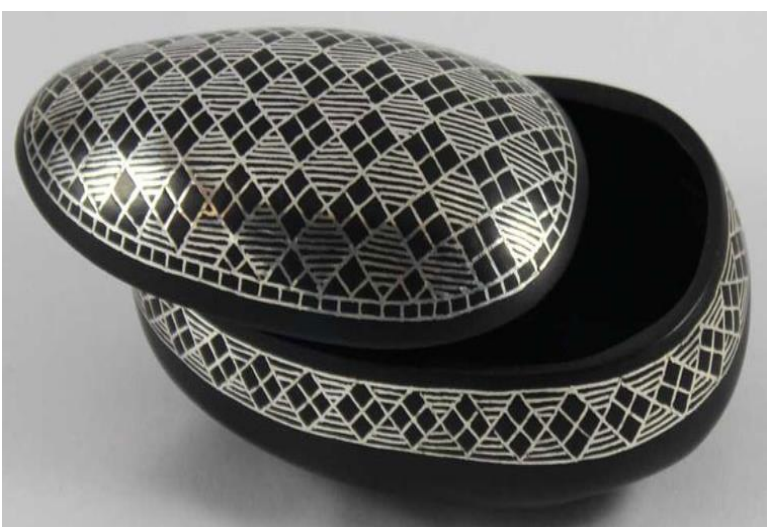
carpenters or weavers who, according to the age-old Indian tradition, belonged to a particular

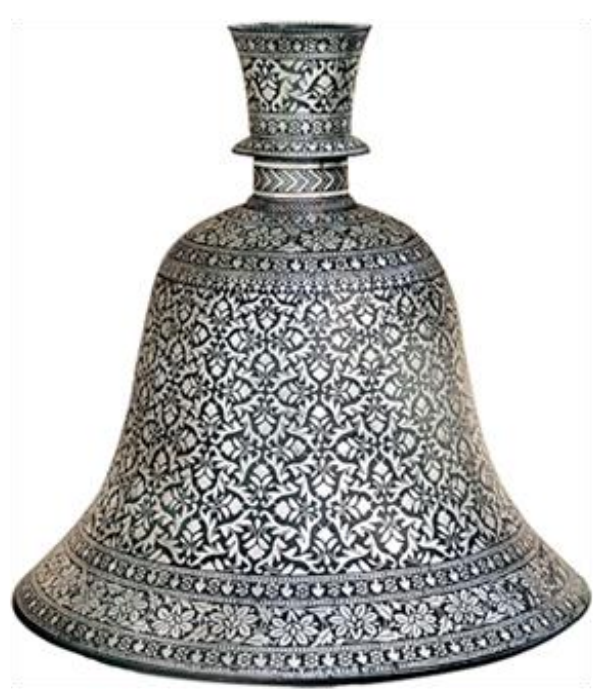
caste of artisans. Men of any caste, Hindu or Muslim, could learn one of its specialized processes of production. In this industry, the role of skilled designer and inlayer was above all others because his contribution was significant for the quality of work." 21

The most reputed craft of Bidri needs sincere attention. The quality of the workmanship is deteriorating, the earlier type of skillful work is not seems today. The government is encouraging for the production and the sale of the Bidri ware. Cooperative workshops cottage industries are being opened. Cluster programme has been organized by the Government and NGO's. The Karnataka Government has created self-help groups of artisans, they get subsidized raw material and other privileges. ${ }^{22}$

\section{REFERENCES}

[1] Pal H. Bhisham Handicrafts of Rajasthan

[2] Imperial Gazetteer of India, Vol III Pg 240

[3] Pal H. Bhisham, Ibid Pg 23-24

[4] Heyne Benjamin, An Account of Bidri ware in India, Asiatic Journal, vol. III, 1817 Pg. 220;Bf: Lal Krishan, Bidri Ware,NewDelhi,1990

[5] Lal Krishan, Bidri Ware,NewDelhi ,1990,Pg 2-3/ http//www.artnewsnviews.com/Bidri ware and Damascene work in Jagdish and Kamala Mittal museum of Indian art

[6] www.britannica.com

[7] Lal Krishan, Ibid,Pg 2-7

[8] Heyne Benjamin, An Account of Bidri ware in India, Asiatic Journal, vol. III, 1817 Pg. 220;Bf: Lal Krishan, Bidri Ware,NewDelhi, 1990 
[9] http://www.idc.iitb.ac.in/dsource/gallery/bidri-ware-hyderabad

[10] Lal Krishan, Ibid,Pg 2-7

[11] Lal Krishan, Ibid,Pg 6-7/www.craftrevival.org

[12] http//www.infinityfoundation.com /Proving their mettle in metal craft

[13] Lal Krishan, Ibid,Pg 6-7

[14] The Censes of India, Vol. II part VII-A(3) 1961; Pg-11

[15] Lal Krishan, Ibid,Pg -7

[16] Jaykar Pupul, Craftsmen and creative the process, India, Ed,Asha Rani Mathur, New Delhi, 1987,Pg- 69

[17] http//www.infinityfoundation.com

[18] www.india-crafts.com/metal-work/bidriware

[19] Lal Krishan, Ibid,Pg -7

[20] Chattopadyay Kamladevi Indias craft tradition Pg 1-09/wwwindi-crafts.com/metal_work / bidriware

[21] http//www.artnewsnviews.com/Bidri ware and Damascene work in Jagdish and Kamala Mittal museum of Indian art

[22] http//www.infinityfoundation.com/Proving their mettle in metal craft

[23] Photograph: courtesy - www.google.com 